Usability: Gaining a Competitive Edge

IFIP World Computer Congress 2002

J. Hammond, T. Gross, J. Wesson (Eds)

Published by Kluwer Academic Publishers

(C) IFIP, 2002

\title{
Usability: Who Cares?
}

\begin{abstract}
An Analysis of Indifference Towards Usability Within the IT Industry
\end{abstract}

Thomas McCoy

Department of Defence, Canberra, Australia

\begin{abstract}
For decades, usability professionals have been seeking to convince the IT industry of the value of their work. However, in the twenty-first century we still find countless application development projects in which usability is ignored. This paper attempts to understand why the situation exists, from economic, psychological and organisational perspectives, and suggests ways of moving forward.
\end{abstract}

Key words: Usability, human-computer interaction, organisation, cost-benefit

\section{INTRODUCTION}

As information technology professionals, our primary mission, above all else, is to create systems that help people to carry out their tasks in an effective and enjoyable way. In other words, to build systems high on usability. Yet, despite the fact that the discipline of human factors has existed since the 1940s, our twenty-first century software development practices still largely ignore the real end-user of the systems we create (Shneiderman \& Gehl, 2000).

The aim of this paper is to examine why this situation exists and to suggest a way forward.

\section{ORGANISATIONAL CONTEXT}

Software development teams create software either for organisations whose core business is software development (e.g. Microsoft, Oracle, 
Adobe) or organisations with another core business (e.g. Coca-Cola, Panasonic, the Department of Defence).

Organisations that develop software for sale on the open market have made some progress towards usability through the establishment of usability testing facilities and laboratories and the engagement of usability professionals (Tremaine, 2001). With the growth in consumer awareness of "ease-of-use", several software development companies now promote their products as being user friendly. Even though the market sectors for many types of software product feature minimal competition, usability will be driven forward by the desire of companies to have their existing user base upgrade to newer versions of their software. Therefore, for software development companies, there will be a natural push towards increasing levels of usability.

The same is not true of organisations whose core business does not involve developing software for the open market. This is the context in which the majority of the world's software development takes place: systems are custom developed to support organisations whose core business is not IT. The systems may be created in-house by the organisation's own staff, or through a contractual relationship with an IT services company. In general, these organisations have not adopted usability practices to any large degree (Catarci et al, 2000) and they are the primary focus of this paper.

\section{BARRIERS TO THE ADOPTION OF USABILITY}

It would be most unusual today to expect a software development team to function without a business or systems analyst (or without people who possess analysis skills), yet most teams develop software in ignorance of usability principles. This is despite ongoing attempts by the usability community to promote its value. Much effort has been expended by usability specialists (Berry, 2001; Bias \& Mayhew, 1994) in targeting the "bottom line" (i.e. trying to demonstrate a return on investment for usability activities) but this has been largely ineffectual (Lund, 1997). What are the factors that have led to something whose value should be beyond question to be ignored?

\subsection{Economic Factors}

\subsubsection{Cost}

To maximise profitability and sharemarket value, companies try to keep costs down. There is no question that doing usability properly (i.e. having it 
integrated into the entire system development life cycle rather than just doing a few tests at the end) is expensive, in the same way as doing anything well is more expensive than mediocrity. Although usability makes promises of cost savings, it requires an up-front investment that is tied to uncertain returns. This makes it unattractive to many managers as shown by the fact that the global amount of money devoted to improving application usability is still only a fraction of what is required (Catarci et al, 2000).

\subsubsection{Time}

Doing usability takes time. Throwing together an application with minimal user involvement, featuring semi-random screen designs that work most of the time, is faster than designing properly. In particular, with today's rapid development environments an application can be an idea at breakfast and implemented after lunch (Spencer, 2000). This relentless time pressure is illustrated in a classic cartoon that shows a project manager leaving his team with the words "I'll go and find out what the users want, the rest of you start coding". While that attitude prevails, there will not be sufficient time allocated to do serious usability work.

\subsection{Psychological Factors}

\subsubsection{Mistrust of IT Promises}

The IT industry is often big on promises and small on results (Harvard Business Review, 1999). The entire usability argument is based on promises: if you use these techniques, you will save $\mathrm{X}$ dollars or gain $\mathrm{Y}$ hours of added productivity or reduce Help Desk calls by $Z$. Managers who have been burnt by vendor promises in the past are unlikely to be receptive to these claims and there is often no follow-up to compare promises with results.

\subsubsection{Glorification of Technology}

The glorification of technology and the worshipping of complexity are further barriers to the widespread adoption of usability techniques. The implicit message here is that machines are clever and humans are stupid. This particularly applies to the many over-engineered user interfaces available today, where even a word processing screen contains more controls than the flight deck of a 767. The inadequacy most people have been taught to feel when confronted with an overly complex user interface compels them to keep quiet. For that reason users often prefer to seek assistance from co- 
workers rather than from IT staff (Shneiderman \& Gehl, 2000) and the reticence of users to express their frustrations openly is a major barrier to usability.

\subsubsection{Separation Between Developers and Users}

The people who develop software are often physically removed from the real end users, and may never meet them or see them operate in their working environment. At design meetings, end users are often represented by their managers, who are generally not the people who will use the application on a day-to-day basis. It has been suggested that substantial "psychological separation" intrinsically exists between software developers and users (Wiebe, 2000) and augmenting this with physical separation means the developers often fail to take account of the concerns of the users. Furthermore, once applications are released, it is rare for developers to see users working with the applications in-situ for any significant period so they remain blind to the effects their work has on others. This leads to an absence of concern for the user.

\subsubsection{Dislike of Usability Professionals}

Most people dislike having their work criticised. The way usability professionals have been used so far (being brought in at the last minute and focusing almost exclusively on usability testing and evaluation) has created resentment among application developers (Dougherty, 2001). The developers generally work under substantial pressure with complex technologies and invest vast amounts of effort into getting applications to work (more or less) correctly. When outsiders, who may not have spent the last month working 100-hour weeks to finish the project on time, are brought in at the end to pass judgement on the work of the developers, the resentment is understandable. In particular, usability professionals often recommend changes that would involve massive re-engineering of the application. The dislike of usability professionals when operating in the "usability police" role does little to advance adoption of usability techniques in organisations.

\subsection{Organisational Factors}

\subsubsection{Powerlessness of End-Users}

The end users of many applications often hold no power in organisations and it is usually their managers who are involved in IT projects. This is even truer when the application will serve users outside the organisation (e.g. a 
job search kiosk application provided by the Department of Employment). After implementation there is generally no significant feedback from end users to project managers. Furthermore, there is often no effective way for users to report their frustrations.

Since the majority of users in organisations work at the clerical level, there tends to be a lack of interest in user difficulties as long as they can "muddle their way through". Only when IT processing comes to a standstill or when deficiencies directly frustrate a senior executive is action usually taken.

\subsubsection{Distribution of Rewards and Punishments}

Software developers are taught, very early in their careers, that the most important factor in climbing the career ladder is to deliver systems on time and within budget (Bloomer \& Croft, 1997). Almost nothing else matters. Rewards are not given for application aspects that are hard to assess, such as quality, reliability, or usability and attention to these aspects by concerned developers could, in fact, jeopardise timely delivery.

Furthermore, in the complex world of software development, staff quickly learn that they have dozens of available excuses for usability deficiencies: "the user is stupid", "that was the only way it could be done", "it will be fixed in the next release", "training will look after it", etc. With powerful structures in place that fail to reward usability and savagely punish late delivery (often against arbitrarily determined deadlines) a major barrier to usability exists in most organisations.

\subsubsection{Separate Budgets for Development and Support}

Companies generally maintain separate budgets for development and support. Understandably, the people running software development will want to minimise their costs, and will be unconcerned if deficiencies in application design result in vastly increased expenditure on support (Norman $\&$ Rohn, 2000) through Help Desk calls, training needs and system fixes.

With nobody keeping an eye on the whole-of-life (i.e. creation to retirement) cost of an application, the real expense of poor usability remains hidden, making companies reluctant to invest in usability expertise. 


\subsection{Other Factors}

\subsubsection{Captive Users}

In general, users have little choice over whether they wish to use a given application. The workplace provides applications and expects staff to use them. Outside their working lives people must interact with a range of applications, such as automatic teller machines, telephone bill-pay services, touch screen kiosks, etc. of which they are "captive users". Where people will be captive users of applications there is little incentive for developers to worry too much about usability.

\subsubsection{Lack of Usability Expertise}

Many organisations would not consider maintaining an in-house usability group or hiring external usability consultants. Even if they did, there is a shortage of usability professionals in many parts of the world. Instead, organisations expect their software developers to look after all aspects of the application (including usability) but most have received no training in this area (Tremaine, 2001), have only the vaguest conception of what usability involves, do not know where to find usability information, and have no incentive to seek it out.

\subsubsection{The Systems Development Life Cycle in Practice}

The systems development life cycle as described in textbooks would have us believe that there is an orderly and steady progression from project inception to completion. In practice, there is a prolonged period of confusion at the start followed by a frantic scramble to finish on time at the end (Wiebe, 2000). This usually results in all "non-essential" activities being jettisoned and, like proper documentation and comprehensive system testing, usability concerns are quickly cast aside in the massive effort to get the application up and running.

\section{SO WHO CARES?}

While many people might care about usability, the factors described above generally prevent them from taking action. The person who would care the most is the end user because, similar to a chef who is asked to work with a blunt knife, the user suffers the frustration and stress of trying to achieve a task with inadequate tools. 
As IT toolmakers we should also care. Apart from having pride in our work, the Codes of Ethics of professional computer societies bind us to ensuring that the systems we build serve our users well.

\section{WHERE TO FROM HERE?}

Translating concern into action in such a multi-faceted problem is difficult and there are no easy answers. However, it is clear that focusing predominantly on cost-benefits is not enough.

The push to have usability incorporated into all systems development life cycles must come from IT professionals. Unlike usability staff, who are often regarded as "outsiders", we are central to the development process and have access and influence within organisations. However, we cannot do this alone. We need assistance from our usability colleagues to provide expertise and from a number of other sources, as shown below.

\subsection{IT Professionals}

Measures that could be taken by us, as IT professionals, include the following.

- Speak out against arbitrary and unrealistic deadlines. Every time project managers acquiesce to these without challenge, usability, along with any "soft" aspect of application development (such as documentation or training), suffers. In the same way as a surgeon asked to perform a triple bypass operation in ten minutes would explain the risks and refuse, IT professionals need to subtly resist being forced into timeframes that would substantially lower quality and usability.

- Request usability expertise within project teams. When assembling teams, project managers should request that somebody with usability expertise be included. This expertise must be readily available for the life of the project (not just at the end) and the usability person would ideally be a permanent team member (and carry the same accountability for project success as the technical staff).

- Acquire knowledge of usability techniques. Many excellent books (Constantine \& Lockwood, 1999; Nielsen, 1993; Shneiderman, 1998; Tognazzini, 1996) and web sites (www.asktog.com, www.nngroup.com, www.useit.com) are available that describe usability in practical terms and do not require specialist human factors knowledge to be understood. As part of their continuing education IT professionals would benefit from learning about usability, thereby being able to build applications that meet with greater user acceptance. 
- Involve project team closely with the end user. Ideally, the project team should be collocated with the end user. If this is not practical they should at least visit the users regularly in their workplace and perhaps even socialise with them. This would help IT people to understand the world of the user. It would be especially useful, upon project implementation, for application developers to "floor walk" the users' workplace and actively look for difficulties.

- Promote the value of usability. This can be done through formal presentations to staff or informally (and perhaps more effectively) via water cooler, corridor and coffee room conversations. Project managers could encourage a usability focus among their staff.

- Empower the users. IT professionals need to treat users with respect and courtesy at all times (even when apparently "stupid" questions are asked). In particular, they need to avoid "defending" applications from criticism and be willing to accept that if a feature caused confusion, a design improvement might be necessary.

\subsection{Organisations}

Senior executives of organisations could, under encouragement from their IT staff, implement these changes.

- Modify reward structures to increase emphasis on quality and usability. The present obsession with "time and budget" encourages the sacrifice of quality and usability for short development cycles. Qualitative aspects of applications should be assessed, valued, and rewarded no less than rapid development. If organisations fail to demonstrate a commitment to quality and usability they risk losing these attributes in their applications.

- Monitor application support costs. The enormous costs of help desks, training and ongoing application maintenance are too often accepted as the inevitable cost of running a computer application. However, many support costs are the result of poor design during application development, particularly in the usability area. Rather than having separate development and support budgets, organisations should consider tracking total costs (development and support) per application. This approach should encourage usability improvements, as the costs of poor usability were made visible.

- Consider establishing a usability group. This would not suit all organisations, but if such a group were established it should be corporately funded (to provide independence from the IT division) and its members should be seconded onto projects as required. The group could become a "centre of excellence" for usability techniques and provide 
regular training for developers and users. There is an increasing tendency these days to subsume usability staff into broader quality assurance groups. Unfortunately, because usability is already such a broad, multi-disciplinary area, this carries the risk of de-skilling staff (as their work becomes too broad to manage) and usability can become sidelined. It also diminishes the collegiate atmosphere present in a team of usability professionals.

- Continuously assess user satisfaction with applications. Many organisations use surveys to do this but people soon suffer "survey fatigue", so face-to-face techniques (particularly in the person's working environment) may be more effective. However, it is important that somebody skilled in interviewing techniques gathers this information and to avoid contaminating the results it should not be the interviewee's supervisor or the application developer. A usability professional would be ideal.

- Provide responsive and friendly reporting mechanisms for problems. Users should be encouraged to report problems and difficulties. In particular, help desk staff should be trained in customer relations to reduce the inadequacy users feel when struggling with applications and dealing with support staff who speak fluent techno-babble.

- Ensure that software development contracts with external suppliers contain detailed usability specifications. Specialist usability advice would be necessary to do this. In particular, there must be a precise specification of how compliance would be assessed. Too often vague requirements such as "the application must be highly usable" are made and these help neither the supplier nor the client.

\subsection{Usability Professionals}

Our colleagues working in usability could take these measures.

- Follow through on promises of usability benefits. Where promises of usability benefits are made, usability professionals could encourage a post implementation review that verifies promises made against results. In the absence of verification promises lose credibility and executives need to be shown what metrics could be used to verify claims.

- Refuse "usability police" roles. If possible, these roles should never be undertaken. Where the usability staff have not worked with and guided the development team throughout the project, the team should not then be subject to external judgement. Usability staff placed in this role (unintentionally) antagonise developers and this may be part of the reason why some are calling for the abolition of the term "usability". 
- Discourage the test/retest strategy. Many IT people view usability as no more than usability testing. However, it must be continually emphasised that starting usability at the final testing stage before implementation is almost always too late. Furthermore, people need to be taught that "one cannot test one's way to good usability" and that usability techniques are of most value during initial design.

- Learn more about software development. Usability professionals can enhance their skills greatly by learning about software development (preferably with some hands-on experience) so they can appreciate the pressures, skills and tradeoffs of a development environment. Without this knowledge they may appear insensitive to the enormous intellectual effort developers invested in creating an application.

\section{$5.4 \quad$ Educational Institutions}

Educational institutions (universities, colleges and private providers) have an enormous part to play in promoting usability.

- Make usability courses a compulsory part of the computing curriculum. Too many IT professionals receive no training in usability or human factors in their formal qualifications. Educational institutions need to respond to this by including compulsory usability courses in current IT-oriented degrees and diplomas and by offering these to past graduates.

- Increase usability course offerings. There are still not enough courses available for usability professionals and these need to be increased, both to attract people into the profession and to allow usability practitioners to upgrade their skills.

\subsection{Professional Computer Societies}

Professional computer societies all over the world are responsible for continuously improving the state of professional IT practice and with their access to members they make valuable allies and could help in the following ways.

- Promote the value of usability to the membership. Computer societies are well placed to promote usability, particularly since it ties in closely with their codes of ethics. This can be done through professional development sessions and through their publications (which have traditionally featured a dearth of usability related articles).

- Include usability in software engineering certifications. People who wish to certify as software engineers or developers should be required to demonstrate competence in usability knowledge and techniques. Current 
certifications, such as the one proposed by the IEEE Computer Society, have not yet included this.

\section{CONCLUSION}

The reasons why few people involved in software development appear to care about usability are many and extend beyond simple cost considerations. To address this problem a prolonged, multi-faceted approach is needed that must be driven "from the inside" by the software developers and by managers.

All of us are, on many occasions, computer users and with the enormous pace of technology uptake, computerisation will touch our lives in ways we cannot imagine. If not for our fellow human beings, we need to take usability seriously for our own sake. I will always remember an executive I worked for who steadfastly refused to invest any time or money in usability activities while cursing out loud whenever he was unable to operate our cantankerous in-house applications.

The fundamental objective of usability is to "match design with need", and when people ask "if your computer were a person, how long till you punch it in the nose?" (John \& Bass, 2001) it is apparent that there is still much work to be done in making usability a central part of the systems development life cycle.

\section{REFERENCES}

Berry, J. (2001), Site usability must enter ROI calculus, InternetWeek, March 2001, p. 69.

Bias R.G. \& Mayhew D.J. (1994), Cost-Justifying Usability, London: Academic Press.

Bloomer, S. \& Croft, C. (1997), Pitching usability to your organisation, Interactions, Nov./Dec. 1997, pp. 18-26.

Catarci, T., Giacinto, M. \& Raiss, G. (2000), Usability and public administration: experiences of a difficult marriage, Proceedings of the Conference on Universal Usability, Arlington, Virginia, USA, pp. 24-31.

Constantine, L. \& Lockwood, L. (1999), Software for Use - A Practical Guide to the Models and Methods of Usage-Centred Design, New York: ACM Press.

Dougherty, D. (2001), Invasion of the usability experts, Web Techniques, 6(2), pp. 90-91.

Harvard Business Review (1999), The Business Value of IT, Boston: Harvard Business Review.

John, B.E. \& Bass, L. (2001), Usability and software architecture, Behaviour and Information Technology, 20(5), pp. 329-338. 
Lund, A.M. (1997), Another approach to justifying the cost of usability, Interactions, May/June 1997, pp. 48-56.

Nielsen, J. (1993), Usability Engineering, Boston: Academic Press.

Norman, D. \& Rohn, J. (2000), Organisational limits to HCI, Interactions, May/June 2000, pp. 36-60.

Shneiderman, B. (1998), Designing the User Interface: Strategies for Human-Computer Interaction, Reading, MA: Addison-Wesley.

Shneiderman, B. \& Gehl, J. (2000), Credit for computer crashes, Ubiquity 1(31).

Spencer, R. (2000), The streamlined cognitive walkthrough method, working around social constraints encountered in a software development company, CHI Letters, 2(1), pp. 353359.

Tognazzini, B. (1996), Tog on Software Design, Reading, MA: Addison-Wesley.

Tremaine, M. (2001), Business: Where do I start, Interactions, Sept./Oct. 2001, pp. 25-28.

Wiebe, R. (2000), Deep realities: the fit of usability in business, ACM Journal of Computer Documentation, 24(4), pp. 220-226. 